\title{
Effects of Intrinsic Layer Thickness on the Short-Circuit Current Density of Crystalline Silicon-Based Solar Cells
}

\author{
Imroatus Soleha ${ }^{1}$, Endhah Purwandari ${ }^{1, a}$ and Endang Haryati ${ }^{2}$ \\ ${ }^{1}$ Department of Physics, Faculty of Mathematics and Natural Sciences, University of Jember, \\ Jalan Kalimantan No. 37 Jember 68121 \\ ${ }^{2}$ Department of Physics, Faculty of Mathematics and Natural Sciences, University of \\ Cenderawasih, Jalan Kampwolker Waena Jayapura 99351 \\ aendhah.fmipa@unej.ac.id
}

\begin{abstract}
The amount of short-circuits current density (Jsc) shown in the results of the electrical characterization of silicon (c:Si)-based solar cell diodes is one of the determinants of device performance. Efforts to increase Jsc are carried out by adding pure silicon to the diode junction, thereby increasing the magnitude of photoelectron generation in the material. In this paper, the insertion of an intrinsic semiconductor at various thicknesses will be analyzed for its effect on the characteristics of the resulting current-voltage density. By using a 2D simulation based on the finite element method, the solution to the equation of a solar cell semiconductor with a $p$-i-n junction structure becomes the basis for calculating the resulting electric current density. The thickness variation of the simulated layer i ranges from $1 \mu \mathrm{m}$ to 15 $\mu \mathrm{m}$, with a constant thickness of $\mathrm{p}$ and $\mathrm{n}$ layers of $0.4 \mathrm{~m}$. The simulation results show that the reduced thickness of the intrinsic layer has a significant effect on the decrease in short-circuit current density.
\end{abstract}

Keywords: Solar Cells, Silicon Crystals, Thickness, Intrinsic Layer, Photoelectrons, Short Circuit Current

\section{Introduction}

Solar energy is one of the energy sources used to supply the energy needs of Solar Power Plants (PLTS). Besides being available for free, the use of solar energy is one of the efforts to reduce human dependence on fossil fuels, namely coal, oil, and natural gas. The public's needs and industries are fulfilled almost $80 \%$ of conventional energy [1]. The potential of solar energy can provide a large contribution if it can be utilized optimally by designing an energy converter device that can supply energy needs. Therefore we need a semiconductor device converting sunlight directly into electrical energy called solar cells [2].

Sunlight is made up of particles known as photons. The conversion process through the photovoltaic mechanism involves photon energy in solar cells. The photon energy that illuminates the solar cell will be absorbed, reflected, or passed by the material. Photons with larger bandgap energies can free electrons from their atomic bonds, and release them into free electrons by leaving holes. These electrons are excited into higher energy levels and behave as charge carriers (current) in electrical potential while storing chemical energy temporarily [3]. The process of forming the pair of charge carriers (electron-hole) is better known as a generation. Silicon is the basic material for making solar cells which has an energy gap of about $1.11 \mathrm{eV}$, so it can absorb more of the sun's spectrum than other materials. Solar cells with crystalline silicon material can produce a large enough conductivity during the photovoltaic conversion process because they have an orderly arrangement of atoms and good electrical properties [2]. 
Solar cell technology has undergone many developments. To increase the efficiency of solar cells, many efforts have been made to expand the absorption capability of the material for a wider range of electromagnetic wave spectrums. For this purpose, the different device geometry and material combinations have many investigated to support the improvement of solar cell performance [4]. The addition of an intrinsic layer in the p-n junction was found to increase the generation of photoelectrons in the material, so that pin junction solar cells have been widely studied. In the p-i-n solar cells, the p-type semiconductor called p-layer is a layer containing holes as the majority charge carrier and electrons as the minority charge carrier. The n-type semiconductor called the n-layer is a layer containing holes as minority charge carriers and electrons as majority charge carriers. While the i-type semiconductor is an intrinsic layer that has the same number of electrons and holes. The photon energy in the i-layer is utilized for the electron excitation process. The i-layer acts as an active layer that determines the generation of charge carriers by photon energy. In this layer, the process of generation (generation) of electron-hole charge carrier pairs and the process of electron-hole recombination occurs. Both generation and recombination, are strongly influenced by the thickness of this i-layer. If the ilayer is too thick, more photons are absorbed, making it more efficient for light absorption [5].

The effect of intrinsic thickness on the calculation of the current-voltage density characteristics of $p$-i-n junction solar cells has been observed numerically by using the finite element method in 1D form [5]. The variation of the thickness of the i-layer used in this study started from $1 \mu \mathrm{m}-3$ $\mu \mathrm{m}$ with multiples of $1 \mu \mathrm{m}$. The simulation produces a current-voltage density characteristic curve with an open-circuit voltage (VOC) of 0.025 volts. The open-circuit voltage is a very small value for silicon materials. The impurity or dopants function applied to the Poisson equation in the simulation does not match the state of each layer. The impurities entered in all three layers are all the same. The charge carriers in the p-layer should be dominated by holes, while the charge carriers in the n-layer are dominated by electrons [6].

Based on this background, this paper will present the characteristics of the short-circuit current density of crystalline silicon-based solar cells, which are observed in more detailed variations in the thickness of the intrinsic layer. Simulations were carried out using Femlab software with geometric structures modeled in 2D. The variation of the thickness of the i-layer carried out is more than $3 \mathrm{~m}$, namely $1 \mu \mathrm{m}-15 \mu \mathrm{m}$ with multiples of $1 \mathrm{~m}$. This is done because to find out how much the ability of the i-layer to increase the current density is obtained. Numerical modeling in this simulation uses the finite element method (MEH). The advantage of the finite element method is that it can model semiconductor materials that have irregular geometric shapes. In addition, it can define the distribution of electric fields and charge carriers that are not linear in each part. The parameters used in this simulation are the parameters obtained from the results of existing experiments and simulations. These parameters are applied to the basic semiconductor equations, namely the Poisson equation and the continuity equation. The results of this study are the charge carrier distribution profile and the current-voltage density characteristic curve. The simulation of the calculation of the current-voltage density characteristics is calculated based on the distribution profile of the charge carriers, both electrons, and holes.

\section{Methods}

The work is begun by setting the geometry in the 2D form of solar cells, which consists of three subdomain areas, namely $\mathrm{p}$-layer, $\mathrm{i}$-layer, and $\mathrm{n}$-layer. The thickness of the $\mathrm{p}$-layer and $\mathrm{n}$-layer 
was $0.4 \mu \mathrm{m}$. Meanwhile, the thickness of the i-layer varies from $1 \mu \mathrm{m}$ to $15 \mu \mathrm{m}$ in multiples of 1 $\mu \mathrm{m}$. The width of the structure is maintained at $1.5 \mu \mathrm{m}$. The next stage after the depiction of the solar cell geometry is the division of the solar cell geometry. The division of the solar cell geometry into small elements (mesh) that are triangular form. The geometry of the $p-i-n$ junction solar cell in the form of 2 dimensions consists of 10 boundaries. Number 1 (anode) and 10 (cathode) are referred to as Dirichlet boundary, while numbers 2, 3, 4, 5, 6, 7, 8, and 9 are called Neuman boundary. The junction area of the p-i layer, the i-n layer ( 4 and 7 ), the anode boundary (1), cathode boundary (10), boundaries (2, 3, 8, and 9) are made smaller (tighter) the mesh size so that the results what you get is more accurate. The geometry of the device is shown in Figure 1.

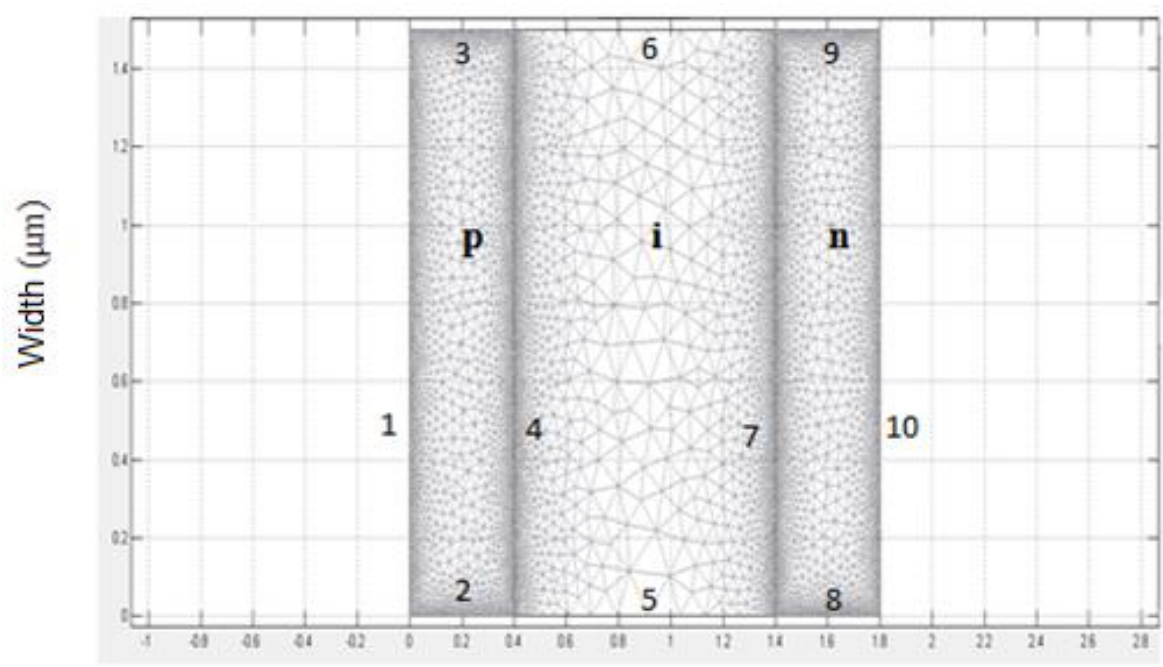

Thickness $(\mu \mathrm{m})$

Figure 1.The division of the geometry of the solar cell device with crystalline silicon (c-Si) 2D structure

The next step after dividing the geometry of the solar cell is to enter the input parameters, the parameters used are under the crystalline silicon (c-Si) material. Parameters used in simulation activities with the finite element method do not use units. Therefore, a scale factor is used so that the values of these parameters are equivalent. The input parameters include distance $(x, y$, $z)$, electric potential $(\psi)$, the concentration of charge carriers $(n, p, N)$, diffusion constant of charge carriers (Dn, Dp), mobility of charge carriers $(\mu n, \mu p)$, and the charge carrier density $(\rho)$. The basic semiconductor equations used in this simulation are the Poisson equation and the continuity equation. The Poisson equation generally describes the phenomenon of changing the electric field in the form of electric potential $(\psi)$ in a device due to the difference in the concentration of charge carriers $(\rho)$. The Poisson equation is a very powerful tool for modeling the behavior of electrostatic systems, but unfortunately can only be solved analytically for very simplified models [7]. Therefore, the solution of the Poisson equation has been conducted by applying numerically by finite element method. Equation 1 describes the Poisson equation modified in Femlab package, where the charge carrier is treated as the total carrier determined by the intrinsic concentration $\mathrm{n}_{\mathrm{i}}$, electric potential $(\Psi)$ applied, and the impurities concentration [8] 
$\nabla^{2} \psi=\frac{\mathrm{q}}{\epsilon}(\rho)=\frac{\mathrm{q}}{\epsilon}\left(\mathrm{n}_{\mathrm{i}} \mathrm{e}^{\psi} \mathrm{u}-\mathrm{n}_{\mathrm{i}} \mathrm{e}^{-\psi_{v}}-\mathrm{N}\right)$

The continuity equation in semiconductor materials is known as the generation and recombination process. The generation process $(G)$ is the process of forming electron-hole pairs per second per cubic meter. While the recombination process $(R)$ is the process of releasing electron-hole pairs per second per cubic meter. From these two processes, it can be seen the value of the current density of charge carriers for both electrons $J_{n}$ and holes $J_{p}$, which is defined in the continuity equation as follows [7]:

$\frac{1}{q} \vec{\nabla} \cdot \vec{J}_{n}=R-G$
$\frac{1}{q} \vec{\nabla} \cdot \vec{J}_{p}=G-R$

Each layer in the $p-i-n$ junction structure has an impurity that defines the dominant charge carrier characteristics. The formulas used for the p-layer, n-layer, and i-layer are shown by equations 4-6, respectively.

$N=\left(N D_{n}+N D_{n \max } e^{-\left(\frac{x 1-x}{c h}\right)^{2}}\right)$

$N=\left(N A_{\text {pmax }} e^{-\left(\frac{x}{c h}\right)^{2}}\right)$

$N=\left(N D_{n}+N D_{n \max } e^{-\left(\frac{x 1-x}{c h}\right)^{2}}-N A_{p \max } e^{-\left(\frac{x}{c h}\right)^{2}}\right)$

where $c h=\frac{\mathrm{ju}}{\sqrt{\log \left(\mathrm{NA}_{\mathrm{pmax}} / \mathrm{ND}_{\mathrm{n}}\right)}}$

$N D n$ is the donor concentration in the n-type region, $N_{n}$ nmax is the highest donor concentration in the $\mathrm{n}$-type region, $\mathrm{NA}_{\mathrm{pmax}}$ is the highest acceptor concentration in the p-type region, ju is the initial layer length $(0.4 \mathrm{~m})$ and $\mathrm{x} 1$ is the thickness of the geometric layer of solar cells $(1.8 \mathrm{~m})$. The process of generation and recombination that occurs in solar cells is mathematically written in the continuity equation. Continuity equations for electrons and continuity equations for holes can be shown in equations 8 and 9 , respectively.

$$
\begin{aligned}
& \frac{1}{q} \nabla \cdot \vec{J}_{n}=\frac{n_{i}(u v-1)}{T_{p}\left(u e^{\psi+1}+1\right)+T_{n}\left(v e^{\psi+1}\right)}-\frac{F \alpha}{1-P}\left(e^{-\alpha x}+P e^{\alpha x}\right) \\
& \frac{1}{q} \nabla \cdot \vec{J}_{p}=\frac{F \alpha}{1-P}\left(e^{-\alpha x}+P e^{\alpha x}\right)-\frac{n_{i}(u v-1)}{T_{p}\left(u e^{\psi+1}\right)+T_{n}\left(v e^{\psi+1}\right)}
\end{aligned}
$$

All parameters supported by the formula are listed in Table 1 . 
Table 1. Parameters in this research

\begin{tabular}{lc}
\hline \multicolumn{1}{c}{ Parameter } & Number \\
\hline Electric charge $(q)$ & $1.602 \times 10^{-19} \mathrm{C}$ \\
Permittivity of vacum $\left(\epsilon_{0}\right)$ & $8.85 \times 10^{-14} \mathrm{~F} / \mathrm{cm}$ \\
Temperature $(\mathrm{T})$ & $300 \mathrm{~K}$ \\
Boltzman Constant $(\mathrm{k})$ & $1.38 \times 10^{-23} \mathrm{~J} / \mathrm{K}$ \\
Intrinsic concentration $\left(\mathrm{n}_{\mathrm{i}}\right)$ & $1.46 \times 10^{10} \mathrm{~cm}^{-2}$ \\
Donor concentration $(\mathrm{NDn})$ & $10^{18} / \mathrm{cm}$ \\
Acceptor concentration $(\mathrm{NDp})$ & $10^{18} / \mathrm{cm}$ \\
Permittivity of silicon $\left(\epsilon_{\mathrm{r}}\right)$ & $11.8 \mathrm{~F} / \mathrm{cm}[9]$ \\
The flux of Photon $(\mathrm{F})$ & $10^{-17} \mathrm{~cm}^{-2} \mathrm{~s}^{-1}[10]$ \\
A factor of transmission $(P)^{* x}$ & $0,023[11]$ \\
Coefficient of light absorption $(\alpha)$ & $10^{4}$ \\
Mobility of electron $\left(\mu_{\mathrm{n}}\right)$ & $800 \mathrm{~cm}^{2} / \mathrm{Vs}[12]$ \\
Mobility of hole $\left(\mu_{\mathrm{p}}\right)$ & $200 \mathrm{~cm}^{2} / \mathrm{Vs}[12]$ \\
Diffusivity of electron $\left(\mathrm{D}_{\mathrm{n}}\right)$ & $20.7 \mathrm{~cm}^{2} / \mathrm{s}$ \\
Diffusivity of hole $\left(\mathrm{D}_{p}\right)$ & $5.17 \mathrm{~cm}^{2} / \mathrm{s}$ \\
Lifetime of electron $\left(\tau_{\mathrm{n}}\right)$ & $2.5 \times 10^{-12} \mathrm{~s}[13]$ \\
Lifetime of hole $\left(\tau_{\mathrm{n}}\right)^{\mathrm{x} \times}$ & $1 \times 10^{-11} \mathrm{~s}[13]$ \\
Mesh & 0.005 \\
Thickness variation $(\mathrm{x})$ & $(1-15) \mu \mathrm{m}$ \\
\hline
\end{tabular}

This research will produce a distribution profile of electron-hole charge carriers and a currentvoltage density curve of $\mathrm{J}-\mathrm{V}$ solar cells based on $\mathrm{c}-\mathrm{Si}$, with variations in the thickness of the $\mathrm{i}$ layer. The observed charge carrier distribution profile is the concentration distribution of the charge carriers, both electrons and holes. The distribution of concentration on the highest electron charge carriers lies in the n-layer, while the concentration distribution on the highest hole charge carriers lies in the p-layer. The parameters observed in the results of the $\mathrm{J}-\mathrm{V}$ current-voltage density curve are the open-circuit voltage $\left(\mathrm{V}_{\mathrm{OC}}\right)$ and short-circuit current density $\left(\mathrm{J}_{\mathrm{SC}}\right)$. The current density obtained is the total current density, which is the sum of the current density caused by the movement of electrons and the current density caused by the movement of holes. The value of the current density in all circuits is the same, therefore in this simulation only observing the current density at boundary 1 . Data analysis was carried out on each $\mathrm{J}-\mathrm{V}$ current-voltage density characteristic curve obtained with variations in the thickness of the ilayer ranging from $1 \mu \mathrm{m}$ to $15 \mu \mathrm{m}$ with multiples of $\mu 1 \mathrm{~m}$. If there is a difference in the $\mathrm{J}-\mathrm{V}$ current-voltage density curve for each variation of the thickness of the i-layer, then the thickness of the i-layer affects the current-voltage density characteristics of the solar cell. The parameter analyzed here is the short circuit current density $\left(\mathrm{J}_{\mathrm{SC}}\right)$ obtained. The greater the short circuit current density generated on the $\mathrm{J}-\mathrm{V}$ characteristic curve, the better the performance of the solar cell.

\section{Results and Discussion}

The calculation of the current density is obtained by applying the voltage input that is of vary at $0-0.45 \mathrm{~V}$. The current density in a semiconductor is caused by the movement of charge carriers, both electrons and holes. In solar cells, electrons move from the n-layer to the p-layer (right to left), while holes move from the p-layer to the n-layer (left to right). Thus, the two movements of 
charge carriers (electrons and holes) form parallel currents that produce an electric current. In this simulation, boundary 1 has hole current density $\left(J_{p}\right)$ as the majority current density and electron current density $\left(J_{n}\right)$ as minority current density. So the total current density at the edge of 1 is the sum of the two current densities. Figure $2-5$ perform the $\mathrm{J}-\mathrm{V}$ characteristic of solar cell device at the thickness of $1 \mu \mathrm{m}, 5 \mu \mathrm{m}, 10 \mu \mathrm{m}$ and $15 \mu \mathrm{m}$, with the thickness of the p-layer and $\mathrm{n}$-layer each remaining equal to $0.4 \mathrm{~m}$.

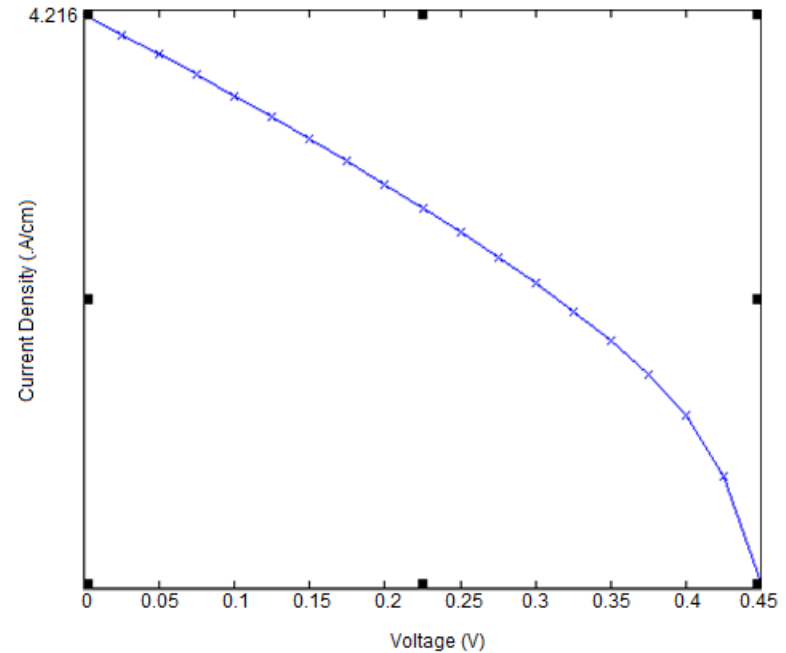

(a)

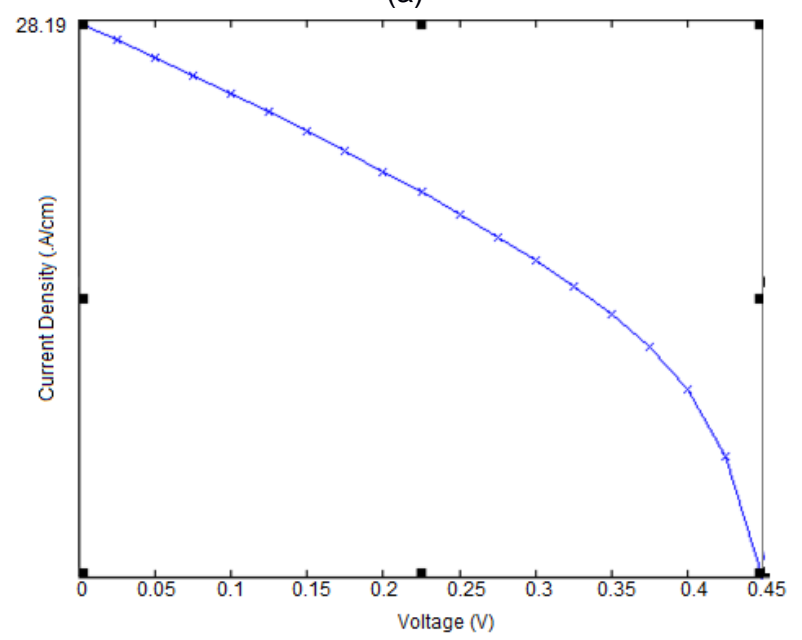

(c)

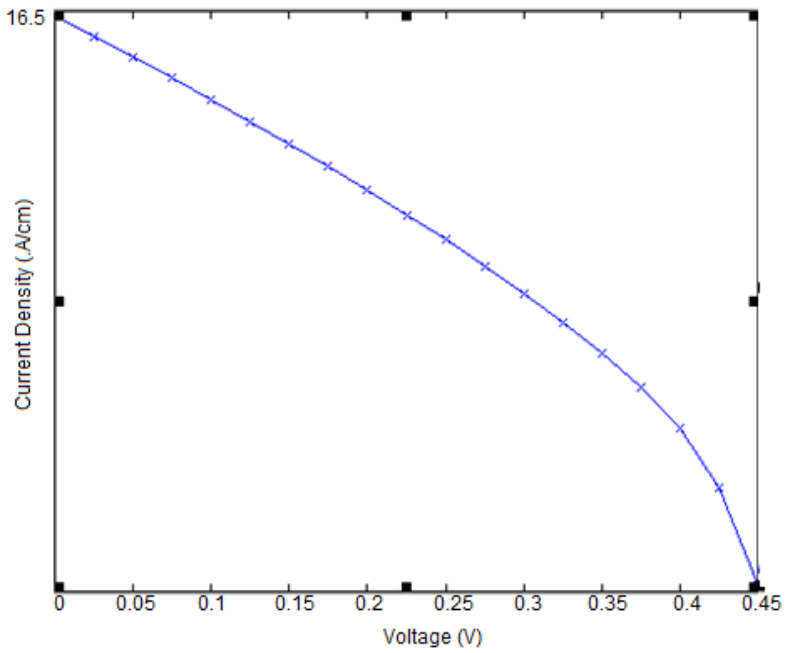

(b)

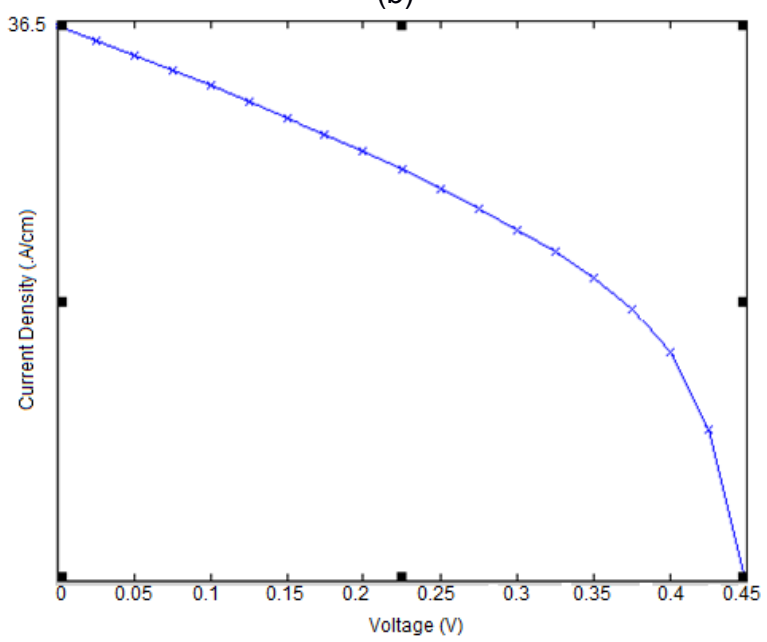

(d)

Figure 2. Current-voltage density $(\mathrm{J}-\mathrm{V})$ characteristic curve of solar cells when the thickness of the p-layer and the n-layer are each fixed at $0.4 \mathrm{~m}$ with the i-layer thickness of (a) $1 \mu \mathrm{m}$, (b) 5 $\mu \mathrm{m},(\mathrm{c}) 10 \mu \mathrm{m}$ and (d) $15 \mu \mathrm{m}$.

The resulting current-voltage density $(\mathrm{J}-\mathrm{V})$ characteristic curve shows the relationship between the total electric current density value and the applied voltage variation. This curve corresponds 
to the characteristic curve of the current-voltage density of solar cells in general. The highest current density curve was obtained when the thickness of the i-layer was made of $15 \mu \mathrm{m}$, while the lowest value was obtained at a thickness of $1 \mu \mathrm{m}$. In this case, the variation of the thickness of the i-layer gives a change in the value of the short circuit current density $\left(\mathrm{J}_{\mathrm{SC}}\right)$, but there is no change in the $\mathrm{V}_{\mathrm{OC}}$. As shown in Figure 2, the increase in the thickness of the i-layer contributes to an increase in the amount of photon energy that can be absorbed by the solar cell. This can be seen from the tendency of increasing $\mathrm{J}_{\mathrm{SC}}$ value when the thickness of the i-layer is increased from $1 \mu \mathrm{m}$ to $15 \mu \mathrm{m}$. At the i-layer thickness of $1 \mu \mathrm{m}, 5 \mu \mathrm{m}, 10 \mu \mathrm{m}$, and $15 \mu \mathrm{m}$, the resulting short-circuit current density is $4.216 \mathrm{~mA} / \mathrm{cm}, 16.50 \mathrm{~mA} / \mathrm{cm}, 28.19 \mathrm{~mA} / \mathrm{cm}$ and $36.50 \mathrm{~mA} / \mathrm{cm}$, respectively. The Jsc for all intrinsic thickness variations is shown in Table 2. The resulting short-circuit current density increases as the thickness of the i-layer increases.

Table 2. The Jsc and Voc of simulated result

\begin{tabular}{ccc}
\hline Thickness $(\mu \mathrm{m})$ & Jsc $(\mathrm{mA} / \mathrm{cm})$ & Voc $(\mathrm{V})$ \\
\hline 1 & 4.216 & 0.45 \\
2 & 7.669 & 0.45 \\
3 & 10.760 & 0.45 \\
4 & 13.670 & 0.45 \\
5 & 16.500 & 0.45 \\
6 & 18.900 & 0.45 \\
7 & 21.440 & 0.45 \\
8 & 24.320 & 0.45 \\
9 & 26.700 & 0.45 \\
10 & 28.190 & 0.45 \\
11 & 28.470 & 0.45 \\
12 & 30.510 & 0.45 \\
13 & 32.150 & 0.45 \\
14 & 34.220 & 0.45 \\
15 & 36.500 & 0.45
\end{tabular}

The short circuit current density (Jsc) performs the increasing number of photocurrents. The increase of the intrinsic layer has successfully increased the number of charge carriers. The use of a higher absorption factor has strengthened the Jsc [14]. Unlike the $J_{S c}$ characteristics, the open-circuit voltage $\left(\mathrm{V}_{\mathrm{OC}}\right)$ obtained in this study is not affected by variations in the thickness of the $\mathrm{i}$-layer. That is, when the thickness of the i-layer is varied from $1 \mu \mathrm{m}$ to $15 \mu \mathrm{m}$, the resulting open-circuit voltage $\left(\mathrm{V}_{\mathrm{OC}}\right)$ does not change. The main factor raising the Voc should be done by tuning up the number of doping concentrations [14]. The resulting open-circuit voltage is a constant value of 0.45 volts, which can be seen in Table 2 .

In previous studies, the characteristics of the current-voltage density $(\mathrm{J}-\mathrm{V})$ of silicon crystalline solar cells have been simulated with the type of $p-i-n$ junction in 1-dimensional form by Herawati [5]. The short-circuit current density produced in this study is greater than that of Herawati's one. The short-circuit current density when the i-layer thickness is $1 \mu \mathrm{m}$ in this study was 4.216 $\mathrm{mA} / \mathrm{cm}$, while in Herawati's result was $0.0526 \mathrm{~mA} / \mathrm{cm}$. The open-circuit voltage produced in this study is also greater than that of Herawati. The open-circuit voltage in this study was 0.45 volts, 
while in Herawati's (2014) study it was 0.025 volts. This is because there are differences in the value of impurities given in the Poisson equation. Herawati used a constant value of impurity in both $p$ and $n$ layers, without taking into account changes in the impurity value as a function of position/thickness. In this study, the impurity value applied to the $\mathrm{p}$-layer and n-layer is an exponential function (equations 4 and 5). The hole concentration will decrease when applied from the $\mathrm{p}$-layer to the n-layer. The electron concentration will increase when calculated from the p-layer to the n-layer. In addition, the absorption coefficient of incident photons used in this study is greater than in previous studies. Therefore, the current density value generated in this study is larger without taking into account changes in the value of impurities as a function of position/thickness. In this study, the impurity value applied to the p-layer and n-layer is an exponential function (equations 4-6). The hole concentration will decrease when applied from the p-layer to the n-layer. The electron concentration will increase when calculated from the $\mathrm{p}$ layer to the n-layer. In addition, the absorption coefficient of incident photons used in this study is greater than in previous studies. The absorption coefficient of the material can describe the number of photons that are absorbed by the material and encourage the creation of free electrons.

\section{Conclusions}

Based on the simulation results and the discussion that has been carried out, it can be concluded that the variation of the thickness of the i-layer from $1 \mu \mathrm{m}$ to $15 \mu \mathrm{m}$ with the thickness of the n-layer and p-layer being kept constant at $0.4 \mathrm{~m}$ affects the characteristics of the short circuit current density Jsc produced by the solar cell. The thicker the i-layer applied, the higher Jsc produced by the solar cell. On the other hand, the thinner the i-layer applied, the lower Jsc produced by the solar cell. The highest Jsc was obtained when the thickness of the i-layer was made $15 \mu \mathrm{m}$, while the lowest value was obtained at a thickness of $1 \mu \mathrm{m}$. The variation of the thickness of the i-layer does not affect the open-circuit voltage (Voc) generated by the solar cells.

\section{References}

[1] N. A. Handayani and D. Ariyanti, 2012, Potency Of Solar Energy Applications In Indonesia, International Journal of Renewable Energy Development, Vol. 1, No. 2, page 33-38.

[2] P. M. Fishbane, S. G. Gasiorowicz, and S. T. Thornton, 1996, Physics for Scientists and Engineers Vol I, Extended Version and Physics for Science and Engineers Vol II Package, 2nd ed. New Jersey: Prentice-Hall.

[3] L. C. Hirst, 2012, Principles of Solar Energy Conversion, Comprehensive Renewable Energy, Vol. 1.

[4] S. V. Litvinenko, A. V. Kozinetz, and V. A. Skryshevsky. 2015. Concept Of Photovoltaic Transducer on A Base of Modified P-N Junction Solar Cell, Sensors and Actuators, A: Physical, Vol. 224.

[5] Y. Herawati, 2014, The Effect of Thickness I-Layer on Calculation of Current-Voltage Characteristics Solar Cells PIN Using Finite Element Method, University of Jember.

[6] A. Ibrahim, 2011, Analysis of Electrical Characteristics of Photovoltaic Single Crystal Silicon Solar Cells at Outdoor Measurements, Smart Grid, and Renewable Energy, Vol. 
02, No. 02.

[7] A. Akinpelu, O. A. Akinojo, M. R. Usikalu, C. A. Onumejor, and T. E. Arijaje, 2018, A Numerical Simulation and Modeling of Poisson Equation for Solar Cell in 2 Dimensions, IOP Conference Series: Earth and Environmental Science, Vol. 173, No.1.

[8] E. Danielsson, 2000, FEMLAB Model Library for Semiconductor Devices, Stockholm: The Royal Institute of Technology, pp. 344-362.

[9] R. S. Yuniarsih, E. Purwandari, M. Misto, E. Supriyanto, and S. Supriyadi, 2018, Built in Potential of a-Si:H Based p-i-n Solar Cell at Different Energy Gap of Intrinsic Layer, Computational And Experimental Research In Materials And Renewable Energy, Vol. 1, No. 1.

[10] E. Purwandari and T. Winata, 2013, Efficiency Calculation Analysis of A-Si:H Solar Cells for Determination of Optimum Filament Temperature in Material Deposition, Jurnal ILMU DASAR, Vol. 14, No. 1.

[11] D. M. Jasruddin and A. Momang, 2009, Development Of Hydrogenated Amorphous Silicon Solar Cell p-i-n in Double PECVD Reactor, Physics Application Journal, Vol. 5, No. 1, pp. 14-21.

[12] E. Purwandari and T. Winata, 2012, Optimasi Tekanan Deposisi dalam Simulasi Efisiensi Sel Surya Berbasis Material a-Si:H, Gradien, Vol. 8, No. 1, pp. 716-721.

[13] C. V. Sánchez, 2001, Thin Film Nanocrystalline Silicon Solar Cells Obtained By Hot-Wire CVD, pp. 1995-1997.

[14] M. S. Yoon, Y. Bo Shim, and Y. G. Han, 2015, Influence of The Thickness and Doping Concentration in $p$ - and n-Type Poly-Si Layers on The Efficiency of A Solar Cell Based on A Carbon Fiber, Journal of the Optical Society of Korea, Vol. 19, No. 2. 